\title{
Editorial
}

Journal of Innate

Immunity

Published online: March 23, 2013

DOI: 10.1159/000350215

\section{Neutrophils in the Innate Immunity Conundrum of Cystic Fibrosis: A CFTR-Related Matter?}

\author{
Véronique Witko-Sarsat \\ Cochin Institute, INSERM U1016, CNRS UMR8104, Université Paris Descartes, Université Paris Diderot, Sorbonne \\ Paris Cité et Laboratoire d'Excellence INFLAMEX Paris, Paris, France
}

Until recently, the main focus of cystic fibrosis has been the function of the CFTR (cystic fibrosis transmembrane regulator) channel in epithelial cells. We know that its failure leads to airway epithelium dehydration, thick mucus accumulation and impaired mucociliary clearance, the hypothesis being that this allows bacterial trapping, resulting in chronic lung infections [1]. However, more than 2 decades after the CFTR cloning, we still do not understand how it relates to lung disease and to the tremendous neutrophil burden that persists within the airways nor why chronic colonization with Pseudomonas aeruginosa develops in cystic fibrosis patients who are supposed to be immunocompetent. Although a general defect in innate immunity is now mooted [1], the question remains: Why don't neutrophils do a better job?

In this issue, Zhou et al. [2] examine phagosomal targeting of CFTR in neutrophils and the impact of the $\Delta F 508$ mutation on this process. Previous studies from this group have already provided evidence that CFTR channel expression in neutrophils and its dysfunction can affect neutrophil chlorination of phagocytosed bacteria [3] and that CFTR-dependent chloride anion transport contributes significantly to $P$. aeruginosa killing by normal neutrophils [4]. The presence of CFTR in neutrophils has remained controversial for years. Its detection has been challenging because of the lack of reliable anti-CFTR antibodies and the low amount of CFTR present in neutrophils. In the current study, Zhou et al. [2] used CFTRstably transfected PLB985 cells to demonstrate that the $\triangle$ F508-mutated CFTR failed to localize in phagosomes. Notably, this was rescued by the CFTR corrector compound VRT-325, thus strongly suggesting that a therapeutic strategy aimed at restoring full CFTR function [5] might also target neutrophils.

One unsolved debate still remains as to whether the dysregulation of innate immunity in cystic fibrosis is acquired or constitutive. Unfortunately, no current animal model (neither mice nor ferrets nor pigs) can accurately mimic the lung disease observed in patients with cystic fibrosis. Nevertheless, some studies have reported that neutrophils from mice expressing the $\triangle \mathrm{F} 508$ CFTR or mice lacking CFTR in myeloid cells have a proinflammatory phenotype after lipopolysaccharide [7] or bacterial [8] challenge thus suggesting that CFTR expression in neutrophils might regulate their function. Since neutrophils are the major cell type and their accumulation is associated with lung failure, it is reasonable to meticulously scrutinize them in cystic fibrosis. The study of heterozygous individuals could provide a unique opportunity to uncover constitutive disturbance, independently of infec-

\section{KARGER}

Fax +4161306 1234

E-Mail karger@karger.ch

www.karger.com
(C) 2013 S. Karger AG, Basel

$1662-811 X / 13 / 0053-0195 \$ 38.00 / 0$

Accessible online at:

www.karger.com/jin
Dr. Véronique Witko-Sarsat

Department of Immunology-Hematology, Cochin Institute, INSERM U1016

27, rue du Faubourg Saint-Jacques

FR-75014 Paris (France)

E-Mail veronique.witko@inserm.fr 
tions, and thus provide some insight into this debate [9]. Previous studies have shown that neutrophils from heterozygous individuals have increased oxidant production [10] as well as a delayed apoptosis [11], thus presumably potentiating their proinflammatory capacity. Interestingly, the delayed apoptosis observed in neutrophils from cystic fibrosis patients and from their parents was not reversed by an inhibitor of CFTR compared with controls, which strongly suggests that CFTR functions in neutrophils may be independent of its chloride channel function. This concept of channel-independent functions is no longer in doubt given the multiplicity of proteins with various functions that have been shown to be associated with CFTR [12].

A number of significant experiments have underscored the importance of neutrophils in innate immunity and their functions appear to extend far beyond their well-described, essential role in antibacterial defense. Thus, one can postulate that a disturbance in neutrophil reprogramming would severely impair the course of an inflammatory challenge. Both the image we have of neutrophils and the immunological conundrum posed by cystic fibrosis have evolved but the troubling question of the role of neutrophils in cystic fibrosis remains [13]. The work of Zhou et al. [2] supports the possibility that the CFTR may be important for human neutrophils to fully achieve their bactericidal capacity. This report is timely, as we urgently need to understand the impact of neutrophil function/dysfunction in cystic fibrosis and how it relates to the CFTR. Moving on from the conventions of the last decade regarding neutrophil functions, this hypothesis of a constitutive disturbance of neutrophils in cystic fibrosis may allow for a true working paradigm with therapeutic implications for today.

\section{References}

1 Cohen TS, Prince A: Cystic fibrosis: a mucosal immunodeficiency syndrome. Nat Med 2012; 18:509-519.

$\checkmark 2$ Zhou Y, Song K, Painter RG, Aiken M, Reiser J, Stanton BA, Nauseef WM, Wang G: Cystic fibrosis transmembrane conductance regulator recruitment to phagosomes in neutrophils. J Innate Immun 2013;5:219-230.

-3 Painter RG, Valentine VG, Lanson NA Jr, Leidal K, Zhang Q, Lombard G, Thompson C, Viswanathan A, Nauseef WM, Wang G, Wang G: CFTR expression in human neutrophils and the phagolysosomal chlorination defect in cystic fibrosis. Biochemistry 2006; 45:10260-10269.

4 Painter RG, Bonvillain RW, Valentine VG, Lombard GA, LaPlace SG, Nauseef WM, Wang G: The role of chloride anion and CFTR in killing of Pseudomonas aeruginosa by normal and CF neutrophils. J Leukoc Biol 2008;83:1345-1353.
5 Becq F, Mall MA, Sheppard DN, Conese M, Zegarra-Moran O: Pharmacological therapy for cystic fibrosis: from bench to bedside. J Cyst Fibros 2011;10(suppl 2):S129-S145.

6 Keiser NW, Engelhardt JF: New animal models of cystic fibrosis: what are they teaching us? Curr Opin Pulm Med 2011;17:478-483.

$\checkmark 7$ Su X, Looney MR, Su HE, Lee JW, Song Y, Matthay MA: Role of CFTR expressed by neutrophils in modulating acute lung inflammation and injury in mice. Inflamm Res 2011;60: 619-632.

$>8$ Bonfield TL, Hodges CA, Cotton CU, Drumm ML: Absence of the cystic fibrosis transmembrane regulator (CFTR) from myeloid-derived cells slows resolution of inflammation and infection. J Leukoc Biol 2012;92:11111122 .

-9 Hayes E, Pohl K, McElvaney NG, Reeves EP: The cystic fibrosis neutrophil: a specialized yet potentially defective cell. Arch Immunol Ther Exp (Warsz) 2011;59:97-112.
10 Witko-Sarsat V, Allen RC, Paulais M, Nguyen AT, Bessou G, Lenoir G, Descamps-Latscha B: Disturbed myeloperoxidase-dependent activity of neutrophils in cystic fibrosis homozygotes and heterozygotes, and its correction by amiloride. J Immunol 1996;157:27282735.

11 Moriceau S, Lenoir G, Witko-Sarsat V: In cystic fibrosis homozygotes and heterozygotes, neutrophil apoptosis is delayed and modulated by diamide or roscovitine: evidence for an innate neutrophil disturbance. J Innate Immun 2010;2:260-266.

12 Ollero M, Brouillard F, Edelman A: Cystic fibrosis enters the proteomics scene: new answers to old questions. Proteomics 2006;6: 4084-4099.

13 Witko-Sarsat V, Sermet-Gaudelus I, Lenoir G, Descamps-Latscha B: Inflammation and CFTR: might neutrophils be the key in cystic fibrosis? Mediators Inflamm 1999;8:7-11. 